Forensic Science International 104 (1999) 117-125

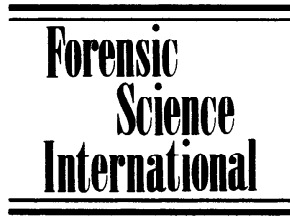

www.elsevier.com/locate/forsciint

\title{
Alcohol use among fatally injured drivers in Spain
}

\author{
M. Carmen del Río, F. Javier Alvarez* \\ Drugs and Alcohol Research Group, Department of Pharmacology and Therapeutics, Faculty of Medicine, \\ University of Valladolid, Valladolid, Spain
}

Received 10 March 1999; received in revised form 13 July 1999; accepted 13 July 1999

\begin{abstract}
Blood from 285 fatally injured drivers in Northern Spain was collected and tested for the presence of alcohol and drugs. Alcohol was detected in 50.5\% of all fatalities. Alcohol alone was detected in $44.2 \%$ of all samples and in the remaining $6.3 \%$ another substance was found together with alcohol. Blood alcohol concentration was classified in different levels. It has been observed that in $35.4 \%$ of the cases the blood alcohol level was $\geq 0.8 \mathrm{~g} / 1$, the legal limit in Spain for car drivers. Alcohol together with other substances was encountered in 18 cases, with medication in $22.2 \%$ (4 out of 18), alcohol with illegal drugs in $66.6 \%$ of the cases (12 out of 18), and alcohol with medicines and illegal drugs in $11.1 \%$ ( 2 out of 18 ). Cocaine was the most commonly detected drug. The study shows how widespread the incidence of a high level of alcohol concentration among drivers involved in fatal accidents in Spain. (C) 1999 Elsevier Science Ireland Ltd. All rights reserved.
\end{abstract}

Keywords: Alcohol; Drugs; Fatal injuries; Traffic accidents; Spain

\section{Introduction}

It has been estimated that more than 2 million people are killed each year in road traffic accident worldwide. Within the European Union, traffic accidents result yearly in 50000 fatalities and 1.5 million injuries. Alcohol plays an increasing role in accidents, as accident severity increases [1]. It has been estimated that alcohol is involved in 19\% of accidents involving injuries and $22 \%$ of serious fatal accidents in the European Union [2].

\footnotetext{
*Corresponding author. Tel.: +34-983-423-077; fax: +34-983-423-022.

E-mail address: alvarez@med.uva.es (F.J. Alvarez)

0379-0738/99/\$ - see front matter (c) 1999 Elsevier Science Ireland Ltd. All rights reserved.

PII: S0379-0738(99)00101-2
} 
The problem of drinking and driving is of special relevance in Spain. This is due, not only to the fact that alcohol consumption is frequent in our country (and, therefore, driving under the influence of alcohol), but also because of an alcohol-related culture: society is very permissive towards its consumption and tolerant towards alcohol-related problems. Furthermore, Spain is one of the European Union countries showing highest figures for road accidents. Consequently, psychoactive drugs and driving are a matter of great interest for developing health policies.

In this regard, a study carried out by our group for the National Traffic Agency (Dirección General de Tráfico), showed how frequent drinking alcohol was among Spanish drivers: $62.9 \%$ of drivers are regular drinkers (drinking at least once a week), drink an average of 46.9 gr/day, with a total of $16.8 \%$ heavy drinkers, consuming more than $80 \mathrm{gr} /$ day. Furthermore, those who drove more frequently are those who drank alcohol more frequently and in a higher quantity [3].

With a population of 39 million, 19.5 million vehicles and 17.2 million drivers ( $34.5 \%$ women), Spain, as mentioned earlier, is one of the European Union countries which has a high incidence of road traffic accidents. 85588 road accidents occurred in 1996, with a toll of 5483 deaths and 124157 injuries, thereby constituting the main cause of death among young people under 30 [4].

However, the magnitude of alcohol and/or drug-related road accidents in our country is not well known. The National Institute of Toxicology produces annual reports including samples sent by forensic doctors or as instructed by a judge for legal purposes, and the indication is that, between 1992 (52\%) and 1996 (49\%) alcohol was detected in just over half the number of road accident victims.

One of the priorities in this context has been to detect alcohol and other substances in road accident victims. The objective of this study has been: (i) to analyse alcohol presence in drivers killed in road accidents; (ii) to determine whether alcohol alone was consumed or mixed with other substances; and (iii) to quantify the amount of alcohol and other substances detected according to various levels.

\section{Material and methods}

This study has been carried out by the University of Valladolid for the National Traffic Agency. It was stated in the said study that all information obtained would be anonymous and used for scientific and not legal purposes. The target population consisted of drivers killed in road accidents (passengers were not included). The data available in each case was: sex, age, day and time of the accident. Samples of venous blood were taken within eight hours of the victim's death and were later sent to our centre.

Samples concerning 285 road accident victims from January 1994 to October 1996 in the north of Spain were obtained. Two hundred and fifty-five (89.5\%) out of the 285 samples analysed were men, and $30(10.5 \%)$ were women. Ninety-six subjects $(33.7 \%)$ were people belonging to the 16-25 age group, 129 (45.3\%) were between 26 and 45 years old and $60(21.0 \%)$ were over 45 . one hundred and thirteen samples $(39.6 \%)$ represented fatally injured drivers on working days (Monday to Friday) and 172 (60.4\%) 
on non-working days (Saturday and Sunday). The average age ( \pm SD) was $34.1 \pm 13.2$ (33.9 \pm 13.1 for men and $36.0 \% \pm 14.7$ for women). $46 \%$ of the samples obtained on non-working days represented people under the age of 26 , whilst on working days the figure was $29 \%$.

Blood samples were analysed for alcohol (ethanol) by Head-Space Gas chromatography. All samples were also screened for the presence of drugs other than alcohol (medicines and illicit drugs) by immunological or chromatographic methods when appropriate. The cut-off levels of the first screening were: opiates $300 \mathrm{ng} / \mathrm{ml}$; cocaine metabolite $150 \mathrm{ng} / \mathrm{ml}$; cannabinoids $20 \mathrm{ng} / \mathrm{ml}$; amphetamines $300 \mathrm{ng} / \mathrm{ml}$ and benzodiazepines $200 \mathrm{ng} / \mathrm{ml}$.

Positive results after screening were confirmed by means of gas chromatography/ mass spectrometry (GC-MS) and concentrations of the psychoactive drugs or metabolites were determined $[2,5,6]$. In the case of opiates, amphetamines and cocaine, the cut-off levels for GC-MS confirmation test were in selected ion monitoring mode (SIM) $50 \mathrm{ng} / \mathrm{ml}$, and $10 \mathrm{ng} / \mathrm{ml}$ in the case of cannabis. Positive results were confirmed by GC-NPFID (nitrogen-phosforus flame-ionization detection) for benzodiazepines (cut-off $0.1 \mu \mathrm{g} / \mathrm{ml}$ ) and for the analgesic drug dipyrone (cut-off $1 \mu \mathrm{g} / \mathrm{ml}$ ).

Substances other than alcohol were classified in two groups: illicit drugs and medicines. Within the first group, categorization into the following groups was established: opiates, cocaine, cannabis, amphetamines, synthetic drugs (ecstasy) and hallucinogenic drugs. Within the second group, different sub-groups were established, in accordance with the Anatomical Therapeutic Chemical classification system.

Once a substance had been detected, samples were classified for this study in the following groups: (i) only with alcohol, (ii) alcohol plus medicines, (iii) alcohol plus illicit drugs, (iv) alcohol plus medicines plus illicit drugs, (v) no alcohol-no drugs.

The concentration of alcohol in the samples was determined, and two scales were established accordingly. The first categorization was adopted, because determination was also made in the study of concentrations of illicit drugs and medicines, the aim being to consider the possible significance of blood concentration. The rating used was based on three levels: low, medium and high concentration (low therapeutic, therapeutic, and high non-therapeutic concentration for medicines), such as has previously been used in other studies for substances other than alcohol [7]. In relation to alcohol, these categories have been established arbitrarily in: level I or low $(0.01-0.49 \mathrm{~g} / 1)$, level II or medium $(0.5-0.99 \mathrm{~g} / 1)$ and level III or high-toxic $(\geq 1 \mathrm{~g} / 1)$. In the second categorization, a double ranking system was used: level I, $0.01-0.79 \mathrm{~g} / \mathrm{l}$; and level $\mathrm{II}, \geq 0.8 \mathrm{~g} / \mathrm{l}$, corresponding to the maximum permitted level in car drivers in Spain.

Analysis of the data was conducted in the Data Processing Center at Valladolid University. Statistics analysis was by means of SAS software version 6.07 (SAS Institute SAS). $P$-Values $<0.05$ were considered to be significant differences.

\section{Results}

Of the 285 samples analyzed, some type of substances were detected in $60 \%(n=171)$ of them. Alcohol was found in 50.5\% $(n=144)$, Illicit drugs in 10.2\% $(n=29)$ and 
Table 1

Incidence of alcohol and/or drugs in fatally injured drivers in Spain

\begin{tabular}{lrr}
\hline & $n$ & $\%$ \\
\hline No substance & 114 & 40.0 \\
& & \\
Some substance & 171 & 60.0 \\
Alcohol & 144 & 50.5 \\
Alone & 126 & 44.2 \\
+ illegal drugs & 12 & 4.2 \\
+ medicines & 4 & 1.4 \\
+ illegal drugs + medicines & 2 & 0.7 \\
Illegal drugs & 29 & 10.2 \\
Alone & 7 & 2.5 \\
+ alcohol & 12 & 4.2 \\
+ medicines & 8 & 2.8 \\
+ medicines + alcohol & 2 & 0.7 \\
Medicines & 26 & 9.1 \\
& & \\
Alone & 12 & 4.2 \\
+ alcohol & 4 & 1.4 \\
+ illegal drugs & 8 & 2.8 \\
+ alcohol + illegal drugs & 2 & 0.7 \\
\hline
\end{tabular}

medicines in $9.1 \%(n=26)$. Regarding alcohol, alcohol alone was detected in $44.2 \%$ $(n=126)$, alcohol plus medicines in $1.4 \%(n=4)$, alcohol plus illegal drugs in $4.2 \%$ $(n=12)$, and alcohol together with illegal drugs and medicines in $0.7 \%(n=2)$ (Table 1).

The percentage of cases in which alcohol was found was greater for men $(54.1 \%)$ than for women $(20.0 \%)$, and also when only alcohol was detected $(47.5 \%$ and $16.7 \%$, respectively); no significant differences were observed between sexes when alcohol, together with other substances, was presented. Significant differences were not observed with regard to the different established age groups (Table 2). The average age of those in whom alcohol was detected was 37.8 years (30.2 for those persons in whom alcohol was accompanied by other substances) (Table 2). Figures relating to alcohol detection were higher on non-working days $(62.8 \%)$ than on working days $(42.4 \%, p<0.001)$.

In $9.5 \%$ of samples analyzed, alcohol concentration was at level I-low-(blood alcohol between 0.01 and $0.49 \mathrm{~g} / 1$ ), $9.1 \%$ at level II -medium- (blood alcohol between 0.5 and $0.99 \mathrm{~g} / \mathrm{l}$ ) and $31.9 \%$ was at level III -high- (blood alcohol concentration $\geq 1 \mathrm{~g} / \mathrm{l}$ ) (Table 3 ). Within grade III, positive cases were more frequent among men (34.5\%) than among women $(10 \%)$, and on non-working days (38.9\%) rather than on working days (27.3\%). The number of samples in which the level of alcohol was above the legal limit in Spain $(\geq 0.8 \mathrm{~g} / \mathrm{l})$ represented $35.4 \%$.

Finally, in Table 4, the presence of other substances together with alcohol is observed and their distribution according to the three levels considered. Of the 18 cases in which alcohol was detected with other substances, cocaine was found in two out of every three 
Table 2

Sociodemographic characteristics of fatally injured drivers testing positive or negative for alcohol and/or drugs

\begin{tabular}{|c|c|c|c|c|c|}
\hline & $\begin{array}{l}\text { Total } \\
n\end{array}$ & $\begin{array}{l}\text { Alcohol } \\
n(\%)\end{array}$ & $\begin{array}{l}\text { Alcohol } \\
\text { only } \\
n(\%)\end{array}$ & $\begin{array}{l}\text { Alcohol and } \\
\text { Drugs } \\
n(\%)\end{array}$ & $\begin{array}{l}\text { Negative } \\
\text { (no alcohol-no drugs) } \\
n(\%)\end{array}$ \\
\hline Total & 285 & $144(50.5)$ & $126(44.2)$ & $18(6.3)$ & $114(40)$ \\
\hline \multicolumn{6}{|l|}{ Sex } \\
\hline Male & 255 & $138(54.1)$ & $121(47.5)$ & $17(6.7)$ & $92(36.1)$ \\
\hline \multirow[t]{2}{*}{ Female } & 30 & $6(20.0)$ & $5(16.7)$ & $1(3.3)$ & $22(73.3)$ \\
\hline & & $P<0.001$ & $P<0.001$ & $\mathrm{n} \cdot \mathrm{s}^{\mathrm{a}}$ & $P<0.001$ \\
\hline \multicolumn{6}{|l|}{ Age } \\
\hline $16-25$ & 96 & $51(53.1)$ & $44(45.8)$ & $7(7.29)$ & $35(36.5)$ \\
\hline $26-45$ & 129 & 67 (51.9) & $57(44.2)$ & $10(7.8)$ & $50(38.8)$ \\
\hline \multirow[t]{2}{*}{$>45$} & 60 & $26(43.3)$ & $25(41.7)$ & $1(1.7)$ & $29(48.3)$ \\
\hline & & n.s & n.s & n.s & n.s \\
\hline Age Mean & & 37.8 & 33.2 & 30.2 & 35.9 \\
\hline SD & & 12.0 & 12.4 & 8.6 & 14.3 \\
\hline \multicolumn{6}{|l|}{ Day } \\
\hline Working & 172 & $73(42.4)$ & $63(36.6)$ & $10(5.8)$ & 77 (44.8) \\
\hline \multirow[t]{2}{*}{ Non-working } & 113 & $71(62.8)$ & $63(55.8)$ & $8(7.1)$ & $37(32.7)$ \\
\hline & & $P<0.001$ & $P<0.001$ & n.s & $P<0.05$ \\
\hline
\end{tabular}

${ }^{\mathrm{a}}$ n.s, not significant.

(66.7\%); in eight cases $(44.4 \%)$ the substance detected was only cocaine, and in another four $(22.2 \%)$ cocaine plus a further substance were found to be present. Opiates were found in two cases, amphetamines in four cases, cannabis in two cases and ecstasy was found in three cases. Benzodiazepines (three cases of diazepam, one bromacepam, one midazolam) were the most commonly detected medicines (27.8\%) together with alcohol, only benzodiazepines with alcohol $(16.7 \%)$ or with other substances $(11.1 \%)$.

\section{Discussion}

Our study shows how often alcohol is detected (50.5\%), either on its own or together with other substances, in the blood samples taken from fatally injured drivers in Spain. Secondly, in a high percentage of cases, the blood alcohol concentration detected was considerable: levels of more than $1 \mathrm{~g} / 1$ were found in $31.9 \%$ of cases and $35.4 \%$ had blood alcohol levels above those permitted in car drivers by law $(\geq 0.8 \mathrm{~g} / 1)$, and. Finally, it should be pointed out that, although in most cases $(87.5 \%)$ only alcohol was found, it was not uncommon (12.5\%) to detect alcohol along with other substances. In our study, cocaine was the most commonly detected drug.

During a recent ICADTS Conference in 1997 [8], we presented a comparison of the data included in this paper (a determination of blood alcohol concentration for non-legal purposes) with that obtained between 1992 and 1995 in the National Institute of 
Table 3

Percentage of fatally injured drivers with BACs above specific limits

\begin{tabular}{|c|c|c|c|c|c|c|c|}
\hline & & \multicolumn{6}{|c|}{ Blood Alcohol Level } \\
\hline & & \multicolumn{2}{|c|}{ Level I } & \multicolumn{2}{|c|}{ Level II } & \multicolumn{2}{|c|}{ Level III } \\
\hline & & \multicolumn{2}{|c|}{$(0.01-0.49 \mathrm{~g} / 1)$} & \multicolumn{2}{|c|}{$(0.5-0.99 \mathrm{~g} / 1)$} & \multicolumn{2}{|c|}{$(\geq 1 \mathrm{~g} / 1)$} \\
\hline & & $n$ & $\%$ & $n$ & $\%$ & $n$ & $\%$ \\
\hline Total & $(285)$ & 27 & 9.5 & 26 & 9.1 & 91 & 31.9 \\
\hline \multicolumn{8}{|l|}{ Sex } \\
\hline Male & $(255)$ & 25 & 9.8 & 25 & 9.8 & 88 & 34.5 \\
\hline \multirow[t]{2}{*}{ Female } & (30) & 2 & 6.7 & 1 & 3.3 & 3 & 10.0 \\
\hline & & & $\mathrm{n} \cdot \mathrm{s}^{\mathrm{a}}$ & & n.s & & $P<0.01$ \\
\hline \multicolumn{8}{|l|}{ Age } \\
\hline $16-25$ & (96) & 20 & 20.8 & 11 & 11.5 & 30 & 31.2 \\
\hline $26-45$ & $(129)$ & 12 & 9.3 & 10 & 7.7 & 45 & 34.9 \\
\hline \multirow[t]{2}{*}{$>45$} & $(60)$ & 5 & 8.3 & 5 & 8.3 & 16 & 26.7 \\
\hline & & & $P<0.05$ & & n.s & & n.s \\
\hline \multicolumn{8}{|l|}{ Day } \\
\hline Working & $(172)$ & 14 & 8.1 & 12 & 7.0 & 47 & 27.3 \\
\hline \multirow[t]{2}{*}{ Non-working } & (113) & 13 & 11.5 & 14 & 12.4 & 44 & 38.9 \\
\hline & & & n.s & & $\mathrm{n} . \mathrm{s}$ & & $P<0.05$ \\
\hline
\end{tabular}

${ }^{\mathrm{a}}$ n.s, not significant.

Toxicology concerning 979 people killed in road accidents (analysis carried out with legal aims). Data from both sources proved very similar; $50.5 \%$ of positive cases in our study compared with $51.3 \%$ in the samples provided by the National Institute of Toxicology. In both cases it was mainly alcohol on its own that was detected, and the number of cases with blood alcohol levels $\geq 0.8 \mathrm{~g} / 1$ in our study represent $35.4 \%$, as against $37.4 \%$ in the National Institute of Toxicology data.

Figures from both sources clearly reveal how common it is to find alcohol in victims of road accidents in Spain. These data have been one of the aspects that have encouraged the authorities to reduce the current legal blood alcohol limits. Spanish legislation establishes legal blood alcohol concentration limits of $0.8 \mathrm{~g} / 1$ in motor-vehicle drivers; $0.5 \mathrm{~g} / 1$ in those driving vehicles over $3.500 \mathrm{~kg}$ and $0.3 \mathrm{~g} / 1$ in those driving vehicles used for transporting passengers and for carrying dangerous goods [4]. Since May 7, 1999 the legal blood alcohol concentration limits have been changed to $0.5 \mathrm{~g} / 1$ in motor-vehicle drivers and $0.3 \mathrm{~g} / 1$ in the other cases.

In any case, figures derived from the National Institute of Toxicology have always been viewed with caution. Firs of all, because samples are only taken to determine alcohol (or other drugs) in very few cases (generally in fewer than 3-5\% of road deaths). How to explain this? Because of what we colloquially refer to as the "widow syndrome": that is to say, no interest is shown as to whether the victim was under the influence of alcohol or not; they would rather the insurance companies paid the families 
Table 4

Level of blood alcohol and substances detected along with alcohol

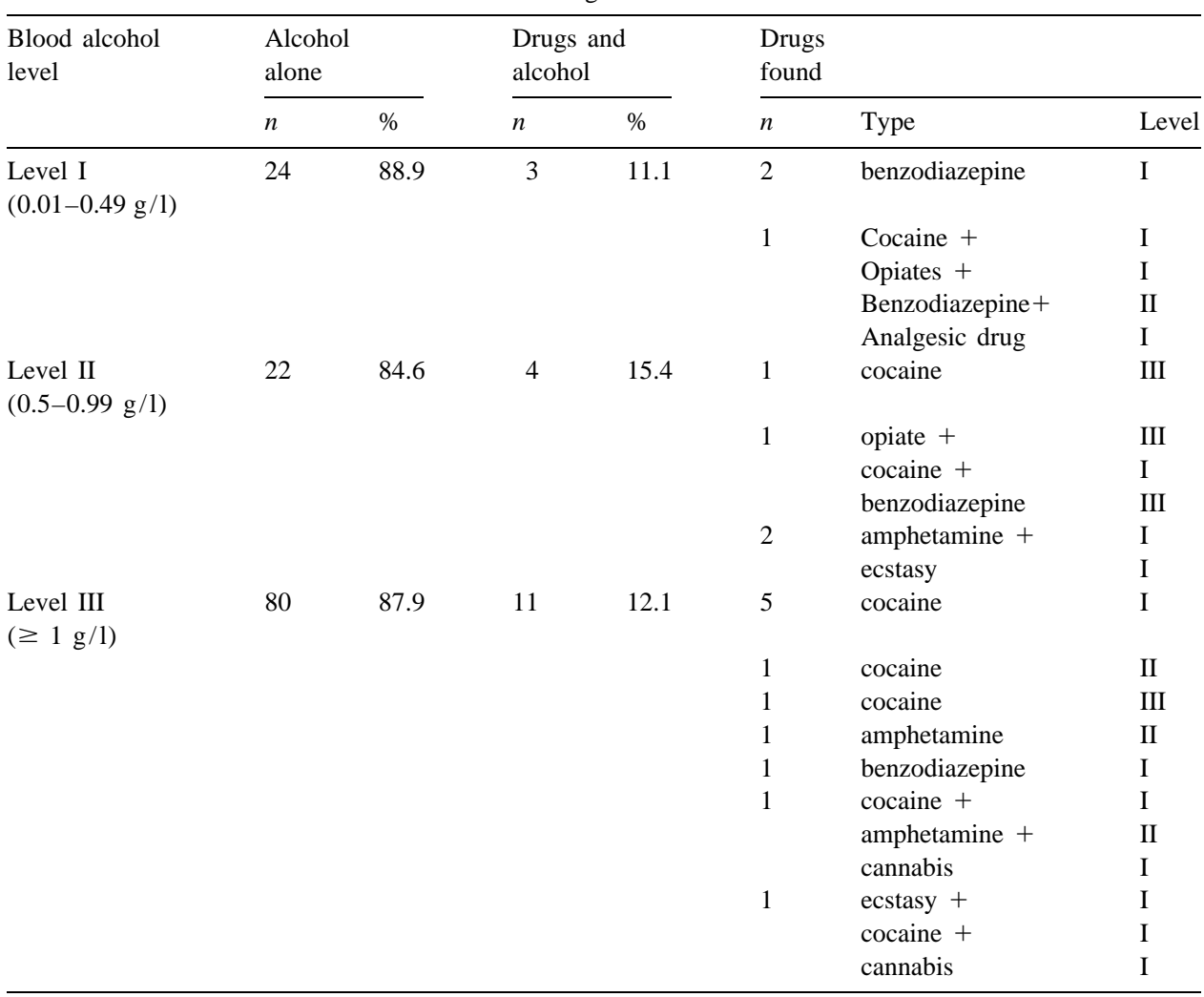

of the victims and the incident was forgotten. Thus, there has always been the fear that blood alcohol (and other drugs) concentration test are carried out only in cases in which the victim has shown clear signs of being either under the effect of alcohol or not. The fact that testing for alcohol in people killed or injured in road accidents has become a formal requirement in Spain since December 1996, might be a means to put an end to that situation.

Although comparison with data from other countries should be carefully made, the figures observed in our study are among the highest $[9,10]$. Within the European Union, perhaps one of the countries with the most complete information is the United Kingdom, through the Coroner's data [11]: data accumulated from 1990 to 1994 revealed that in $45.5 \%$ of deaths alcohol was detected, and that this exceeded $0.8 \mathrm{~g} / 1$ in $20.25 \%$ of victims. Alcohol has been frequently detected in Italy (49.0\%) [10] and in Belgium ( $28 \%$ over $0.49 \mathrm{~g} / 1$ ) [12], whilst figures for the Nordic countries (Sweden: $27 \%$ [13] and $20.3 \%$ [14], Norway: $28.3 \%$ [15]) are considerably lower, perhaps as a result of the fact that in these countries there exists a very strict policy with regard to alcohol and driving.

Data from the Fatality Analysis Reporting System (FARS) show that alcohol involvement in fatal road accidents has been decreasing in the United States in the last 
years [16-18], although in certain studies alcohol has been often found (46\%) [19]. High figures have also been recorded for Canada (48\%) [20], whereas in Australia figures are lower (36\%) [7].

In addition, as regards the association between alcohol and drugs, the frequency with which this is detected varies greatly $4.0 \%$ [14], 11.45\% [20], 13\% [19], as do the types of substances found.

In 1995 two reports examined drink-driving in the European Union [21,22] considering the role of different countermeasures and making recommendations. Drink-Driving does have to be tackled in an integrated and multidisciplinary way. A reduction in the legal blood alcohol limit, has been widely thought to be the next step. Many drivers look to these legal limits as a guide to safe drink-driver's levels, and one suggestion is the harmonisation of maximum blood alcohol concentrations at $0.5 \mathrm{~g} / 1$ throughout the European Union [23]. At present most of the European Union countries have changed this limit.

But besides this measure, other preventive programs also need to be undertaken. Different research [9] shows that only reducing the legal limit would be effective. Experience shows that a much more significant, sustained and long-term impact could be achieved by a four-point program. These vital four measures are: stricter enforcement; tougher punishment; rehabilitation schemes; continuous public education and publicity.

In our country drinking alcohol forms part of many people's daily and social life, and great tolerance and permissiveness exist with regard to alcohol, thereby making intervention in this area rather difficult. However, a great effort is being made with regard to preventive policies, including the reduction of the legal limit, as mentioned earlier.

The present study shows how widespread alcohol is and its high concentration level in the blood of fatally injured drivers, and suggest that drugs other than alcohol (fundamentally illegal drugs) are present in and causally related to impairment resulting in fatal traffic accidents. Cocaine together with alcohol, is the most frequent drug detected. Alcohol is the main problem in traffic fatalities in Spain, thereby making it necessary to intensify efforts and to set up specific programs to reduce drinking and driving, while also clarifying the role of drugs other than alcohol in traffic accidents.

\section{Acknowledgements}

Support for this study was provided by the Dirección General de Tráfico (Traffic National Agency), Ministerio del Interior (Home Office), Madrid, Spain.

\section{References}

[1] European Comission white paper on transport policy (COM 92/494). European Commision, Brussels, 1992.

[2] P. Lillsunde, Drugs and Driving. Analítical and Epidemiological Aspects, The National Public Health Institute, Helsinki, 1996. 
[3] F.J. Alvarez, M.C. Del Río, R. Prada, Drinking and Driving in Spain, J. Stud. Alcohol 56 (1995) 403-407.

[4] Dirección General de Tráfico, Road Safety in Spain. 1996 Report. Dirección General de Tráfico, Madrid, 1996.

[5] M.A. Peat, B.S. Finkle, Toxicological assay of psychoactive substances in biological fluids, in: S.D. Ferrara, R. Giorgetti (Eds.), Methodology in Man-machine Interaction and Epidemiology On Drugs and Driving Safety, ARFI, Padova, 1992, pp. 95-109.

[6] L. Tedeschi, G. Frison, F. Castagna, S.D. Ferrara, Compresive EIA/GC screening and GS-MS confirmation of psychoactive substances and blood and urine, in: S.D. Ferrara, R. Giorgetti (Eds.), Methodology in Man-machine Interaction and Epidemiology On Drugs and Driving Safety, ARFI, Padova, 1992, pp. 147-185.

[7] O.H. Drummer, Drugs in Drivers Killed in Australian Road Traffic Accidents: the Use of Responsibility Analysis To Investigate the Contribution of Drugs To Fatal Accidents, Monash University, Victoria, 1994.

[8] F.J. Alvarez, M. Sancho, J. Vega, M.C. Del Rio, A. Rams, D. Queipo, Alcohol involvement in fatal road accidents in spain, in: C. Mercier-Guyon (Ed.), Alcohol, Drugs and Traffic Safety T'97, Vol. vol. 2, CERMT, Annecy, 1997, pp. 745-750.

[9] A. Clayton, Which Way Forward? A Review of Drink Driving Countermeasures in Selected Countries World-wide, The Portman Group, London, 1997.

[10] S.D. Ferrara, R. Giorgetti, S. Zancaner, Psichoactive substances and driving: state of the art and methodology, Alcohol and Drugs and Driving 10 (1994) 1-55.

[11] G. Maycock, Drinking and Driving in Great Britain - A Review, Transport Research Laboratory, Berkshire, 1997.

[12] Belgian Toxicology and Trauma Study Research Group. Belgian Toxicology and Trauma Study, Ministry for Transport and Infrastructure and the Ministry for Public Health, Brussels, 1996.

[13] M. Ostrom, H. Sjogren, A. Erikson, Role of alcohol in Traffic Crashes Involving Women: Passanger Car Fatalities in Northern Sweden, J. Stud. Alcohol 56 (1995) 506-512.

[14] S. Harmeet, U. Bjornstig, A. Eriksson, U. Ohman, A. Solarz, Drug and Alcohol Use Among Injured Motor Vehicle Drivers in Sweden: Prevalence, Driver, Crash, and Injury Characteristics., Alcohol Clin. Exp. Res. 21 (1997) 968-973.

[15] H. Gjerde, K.M. Beylich, J. Morland, Incidence of alcohol and drugs in fatally injured car drivers, Accid. Anal. Prev. 25 (1993) 479-483.

[16] T.S. Zobeck, B.F. Grant, F.S. Stinson, D. Bertolucci, Alcohol involvement in fatal traffic crashes in the United States 1979-1990, Addiction 89 (1994) 227-231.

[17] R.B. Voas, J. Wells, D. Lestina, A. Williams, M. Greene, Drinking and driving in the United States: the 1996 National Roadside Survey, Accid. Anal. Prev. 30 (1998) 267-275.

[18] A. Anonimo, Alcohol related traffic crashes and fatalities among youth and young adults. United States, 1982-1994, MMWR 44 (1995) 869-874.

[19] B.K. Logan, E.W. Schwilke, Drug and Alcohol Use in Fatally Injured Drivers in Washington State, J. Forensic. Sci. 41 (1996) 505-510.

[20] G.W. Merced, W.K. Jeffery, Alcohol, Drugs, and impairment in fatal traffic accidents in British Columbia, Accid. Anal. Prev. 27 (1995) 335-343.

[21] European Transport Safety Council. Reducing traffic injuries resulting from alcohol impairment, European Transport Safety Council, Brussels, 1995.

[22] Directon Générale des Transports de la Comimission Européenne. L'alcohol, les drogues et les medicaments et securité routiére. Direction Générale des Transports de la Commission Européenne, Brussels, 1995 (VII/392/1995).

[23] F.J. Alvarez, M.C. Del Río, Alcohol and driving [commentary], The Lancet 347 (1996) 985-986. 